\title{
Honestly and carefully assessing outcomes of dorsal lumbotomy incision for pyeloplasty in children
}

\author{
Barry Kogan, MD \\ The Urological Institute of NENY, Albany, NY
}

See related article on page 435.

Cite as: Can Urol Assoc J 2012;6(6):440. http://dx.doi.org/10.5489/cuaj.12334

$\mathrm{T}$ he authors perform a careful and thorough review of the outcome of the use of a dorsal lumbotomy incision for pyeloplasty in children. ${ }^{1}$ They conclude that the operation can be done with good success in older children. Years ago Gil-Vernet popularized the incision in adults, mostly for stone surgery, ${ }^{2}$ and this information supports the results presented.

More importantly, Cloutier and colleagues should be congratulated on this careful review. Often surgeons claim high success rates and minimal morbidity, without honestly and completely evaluating their personal results. I think a few points are notable in this series. The authors note that there was patient selection. We know that they excluded patients with a high body mass index. It would be useful to the reader to know if there were other exclusions (e.g., a proximal ureteral obstruction that might be hard to reach through the incision or a small intrarenal pelvis). Certainly, if the reader were to adopt this technique, they should be fully aware of the case selection. If the authors are promoting this technique over a flank incision, the results are a little disappointing. By North American standards, the length of stay (although the series extends back 10 years) and success rates are suboptimal. Part of the issue may be related to pain control. The authors do not mention the use of ketoralac. In many centres, this has virtually eliminated narcotic use and has facilitated next day discharge. In addition, a success rate of $89 \%$ to $90 \%$ is less than expected in 2012 . Do the authors feel this relates to the limitations of the incision?

In summary, the authors give a systematic and honest appraisal of this operation and, as they note, this is essential if we are to compare historic outcomes to the newer laparoscopic approaches. Finally, next time it would be useful to have some assessment of cost. We are constantly striving to improve the value of the services we provide and cost is an important part of that equation.

Competing interests: None declared.

\section{References}

1. Cloutier J, Haidar N, Rompre-Deschenes M-P, et al. Study comparing the applicability of dorsal lumbotomy in older children. Can Urol Assoc J 2012;6:435-9. http://dx.doi.org/10.5489/cuaj.10064. Epub May 1, 2011.

2. Gil-Vernet J. New Surgical Concepts in Removing Renal Calculi. Urol Int 1965;20:255-88. http://dx.doi. org/10.5489/000279382

Correspondence: Dr. Barry Kogan, Community Care Physicians, PC, 25 Hackett Blvd. MC 208, The Urological Institute of NENY, Albany, NY 12208; bkogan@communitycare.com 